\title{
PENERAPAN METODE PEMBELAJARAN GROUP TO GROUP EXCHANGE DENGAN MEDIA MIND MAPPING UNTUK MENINGKATKAN HASIL BELAJAR BIOLOGI SISWA
}

\author{
Arwin Arif ${ }^{1}$, Ahmad Hasyim ${ }^{2}$ \\ Program Studi Pendidikan Biologi,PMIPA, STKIP Pembangunan Indonesia \\ J1. Inspeksi Kanal Citra Land No. 10 Makassar \\ e-mail : Arwinarif29@gmail.com
}

DOI : 10.35719/alveoli.v2i2.53

\begin{abstract}
This research is a Classroom Action Research which aims to determine the increase in Biology Learning Outcomes through the Group to Group Exchange Learning Method with Mind Mapping Media. The subjects of this study were 20 students of class VIII SMPN 6 Lembor Selatan, West Manggarai Regency in the odd semester of the 2019/2020 school year. The implementation of this research consisted of two cycles and the data collected were analyzed using descriptive. Based on the data the results of the study showed that the Group learning method to Group Exchange using Mind Mapping media has a positive impact in improving student learning outcomes which are marked by an increase in student learning completeness in each cycle, In the first cycle the average score of activity was 38.90, increasing in the second cycle with an average score of 72.78. Mean while, the number of students who did not complete the first cycle by an average of $65 \%$ decreased in the second cycle by an average of $10 \%$. The use of the Group To Group Exhange method with Mind Mapping media can improve student learning outcomes in class VIII students of SMPN 6 Lembor Selatan.
\end{abstract}

Keywords: Group to Group Exchange, Mind Mapping and Learning Outcomes

\begin{abstract}
Abstrak : Penelitian ini adalah Penelitian Tindakan Kelas yang bertujuan untuk mengetahui peningkatan Hasil Belajar Biologi melalui Metode Pembelajaran Group to Group Exchange dengan Media Mind Mapping. Subjek penelitian ini sebanyak 20 orang siswa kelas VIII SMPN 6 Lembor Selatan Kabupaten Manggarai Barat pada semester ganjil tahun ajaran 2019/2020.Pelaksanaan penelitian ini terdiri atas dua siklus dan data yang terkumpul dianalisis dengan menggunakan deskriptif.Berdasarkan data hasil penelitian menunjukkan bahwa metode pembelajaran Group to Group Exchange dengan menggunakan media Mind Mapping memiliki dampak positif dalam meningkatkan hasil belajar siswa yang ditandai dengan peningkatan ketuntasan belajar siswa dalam setiap siklus. Pada siklus I skor rata-rata aktivitas 38,90 meningkat pada siklus II dengan rata-rata 72,78. Sedangkan jumlah siswa yang tidak tuntas pada siklus I dengan rata-rata $65 \%$ menurun pada siklus II dengan rata-rata $10 \%$. Penggunaan metode Group To Group Exhange dengan media Mind Mapping dapat meningkatkan hasil belajar siswa pada siswa kelas VIII SMPN 6 Lembor Selatan.
\end{abstract}

Kata Kunci:Group to Group Exchange,Mind Mapping dan Hasil Belajar 
Pendidikan merupakan suatu proses dalam rangka mempengaruhi peserta didik supaya mampu menyesuaikan diri sebaik mungkin dengan lingkungannya,Dengan demikian akan menimbulkan perubahan dalam dirinya yang memungkinkan berfungsi dalam kehidupan masyarakat. Pengajar bertugas mengarahkan proses ini agar sasaran dari perubahan itu dapat tercapai sebagaimana yang diinginkan (Hamalik, 2005). Meski upaya itu telah dilakukan namun kenyataannya masih terdapat kekurangan yang harus dibenahi.Kekurangan yang paling mendasar dan sangat dirasakan pada pendidikan formal (sekolah) dewasa ini adalah masih rendahnya daya serap siswa. Hal ini nampak pada hasil belajar peserta didik yang masih sangat memprihatinkan (Trianto, 2007).

Metode Group to Group Exchange merupakan pembelajaran kelompok yang melatih peserta didik untuk bekerjasama dalam kelompok. Strategi ini gabungan dari metode diskusi, tanya jawab, dan mengajarkan teman sebaya. Dengan strategi ini peserta didik yang pasif akan dituntut untuk lebih aktif dalam kegiatan kelompok baik diskusi, presentasi, serta tanya jawab (Silberman, 2010). Mind mapping adalah alat pilihan untuk menajamkan ingatan.Mind mapping dapat bekerja dengan baik karena ia mengunakan kedua pemain utama dari ingatan yaitu imajinasi dan asosiasi. Metode mind mapping sangat baik digunakan sebagai pengetahuan awal siswa untuk menemukan alternatif jawaban suatu soal (Buzan, 2004).

Hasil belajar merupakan bagian dari suatu rangkaian proses pembelajaran. Pemiihan pembelajaran dengan menggunakan metode Group to Group Exchange dengan media mind mapping diharapkan lebih efektif, karena siswa akan belajar lebih aktif dan lebih mudah memahami materi pelajaran. Salah satu penilaian hasil belajar adalah untuk mengetahui sejauh mana siswa telah mencapai hasil belajar yang telah direncakan sebelumnya (Majid, 2005).

Berdasarkan wawancara yang dilakukan peneliti dengan guru bidang studi IPA di SMPN 6 Lembor Selatan mengenai hasil belajar siswa kelas VIII yang belum optimal.Hal ini dapat dilihat dari nilai rata-rata ulangan harian siswa kelas VIII disemester II sekarang ini masih banyak siswa yang belum mencapai batas nilai kriteria ketuntasan minimal (KKM) yaitu nilai 66. Banyak faktor yang menyebabkan siswa memperoleh nilai dibawah KKM antara lain: pertama, perbedaan inteligensi siswa yang satu dengan yang lainnya sehingga daya tangkap yang diperoleh pun berbeda. Kedua, siswa kurang berminat dengan materi pelajaran IPA dan penggunaan metode ceramah saja, sehingga membuat siswa menjadi bosan akibatnya minat siswa menjadi rendah dan menurun. Partisipasi siswa dalam mengikuti pembelajaran IPA pun, yang terkadang siswa ramai sendiri dengan temannya ketika mengikuti pembelajaran.

Penggunaan metode pembelajaran Group to Group Exchange dengan Media Mind Mapping dalam pembelajaran Biologi diharapkan dapat meningkatkan hasil belajar siswa. Dengan berpihak pada persoalan yang ada, maka hal itulah yang mendorong bagi penulis untuk melakukan penelitian tentang "Penerapan metode Group to Group Exchange dengan media Mind Mapping untuk meningkatkan hasil belajar Biologi pada materi Pertumbuhan dan Perkembangan Makhluk Hidup kelas VIII SMPN 6 Lembor Seletan’? 


\section{METODE}

Penelitian ini adalah penelitian tindakan kelas yang pelaksanaannya melalui beberapa tahap. Adapun beberapa pelaksanaan meliputi pelaksanaan (plaining), tindakan (action), pengamatan (Observasi), refleksi (reflection), selanjutnya tahapan-tahapan tersebut dapat dirangkai dalam satu siklus kegiatan.Penelitian dilakukan di SMPN 6 Lembor Selatanjalan Poros Selatan.

Subjek penelitiannya adalah siswa kelasVIII SMPN 6 Lembor Selatan sebanyak 20 siswa yang terdiri dari 8 orang laki-laki dan 12 orang perempuan dan memiliki karakteristik yang berbeda-beda. Faktor yang diselidiki dalam pelaksanaan penelitian adalah hasil belajar siswa, guru menilai hasil belajar siswa dengan memberikan tes atau alat penelitian yang telah disediakan.

Prosedur pelaksanaan penelitian tindakan kelas ini terdiri dari dua siklus. Dimana antara silklus I atau siklus II merupakan rangkaian kegiatan yang saling berkaitan, dalam arti dalam pelaksanaan tindakan siklus II merupakan tindak lanjut dan perbaikan dari siklus I.Alat pengumpulan data berupa soal tes pilihan ganda dan essay yang jumlahnya 25 nomor yang diberikan setelah melakukan proses pembelajaran per siklus. Data yang terkumpul akan di analisis secara statistic dekriptif dengan pengkategorian hasil belajar per siklus. Kriteria hasil belajar siswa mengunakan rata-rata sekurang-kurangnya siswa lulus secara klasikal sebanyak 80, siswa lulus secara individual jika nilai yang diperoleh $75 \%$.

\section{HASIL}

Dalam penelitian ini ada dua siklus yang dilaksanakan yaitu siklus I dan siklus II, dari kedua siklus tersebut dapat diketahui sejauh mana tingkat keberhasilan siswa dalam proses Kegiatan Belajar Mengajar (KBM) dengan menerapkan Group to Group Exchange dengan media Mind Mapping dengan memperhatikan aktivtas belajar siswa sebagai ciri khas penelitian tindakan kelas.

\section{PEMBAHASAN}

\section{a) Aktivitas Belajar Siswa}

Data aktivitas siswa selama proses pembelajaran berlangsung diambil dengan menggunakan lembar observasi yang telah disediakan,sebagaimana disajikan dalam tabel sebagai berikut : 
Tabel 1. Aktivitas Belajar Siswa Pada Siklus 1

\begin{tabular}{llllllll}
\hline \multirow{2}{*}{ No } & \multirow{2}{*}{ Aktivitas Siswa } & \multicolumn{2}{c}{ Pert.1 } & \multicolumn{2}{c}{ Pert.2 } & \multirow{2}{*}{ Rata } \\
\cline { 3 - 6 } & & F & $\%$ & F & $\%$ & Rata \\
\hline 1 & Penjelasan guru & 7 & 35 & 10 & 50 & 42,5 \\
\hline 2 & Pengajuan pertanyaan & 4 & 20 & 8 & 40 & 30 \\
\hline 3 & Menjawab pertanyaan & 6 & 30 & 8 & 40 & 35 \\
\hline 4 & Mengajukan tanggapan & 3 & 15 & 7 & 35 & 25 \\
\hline 5 & Kekauan siswa & 12 & 60 & 7 & 35 & 25 \\
\hline 6 & Kerjasama kelompok & 5 & 25 & 12 & 60 & 42,5 \\
\hline 7 & Meminta bimbingan guru & 15 & 75 & 13 & 65 & 70 \\
\hline 8 & Menyimpulkan jawaban & 7 & 35 & 10 & 50 & 42,5 \\
\hline 9 & Kegiatan diluar KBM & 8 & 40 & 5 & 25 & 15 \\
\hline Total Nilai Rata-rata & & & 38,90 &
\end{tabular}

Tabel 2. Aktivitas Belajar Siswa Pada Siklus 2

\begin{tabular}{llllllll}
\hline \multirow{2}{*}{ No } & \multirow{2}{*}{ Aktivitas Siswa } & \multicolumn{2}{c}{ Pert.1 } & \multicolumn{2}{c}{ Pert.2 } & \multirow{2}{*}{ Rata } \\
\cline { 3 - 6 } & & F & \% & F & \% & Rata \\
\hline 1 & Penjelasan guru & 18 & 90 & 19 & 95 & 92,5 \\
\hline 2 & Pengajuan pertanyaan & 15 & 75 & 17 & 85 & 80 \\
\hline 3 & Menjawab pertanyaan & 17 & 85 & 18 & 90 & 87,5 \\
\hline 4 & Mengajukan tanggapan & 14 & 70 & 19 & 95 & 82,5 \\
\hline 5 & Kekauan siswa & 7 & 35 & 2 & 10 & 22,5 \\
\hline 6 & Kerjasama kelompok & 17 & 85 & 19 & 95 & 90 \\
\hline 7 & Meminta bimbingan guru & 17 & 85 & 18 & 90 & 87,5 \\
\hline 8 & Menyimpulkan jawaban & 18 & 90 & 19 & 95 & 92,5 \\
\hline 9 & Kegiatan diluar KBM & 5 & 25 & 3 & 15 & 20 \\
\hline Total Nilai Rata-rata & & & $\mathbf{7 2 , 7 8}$ &
\end{tabular}




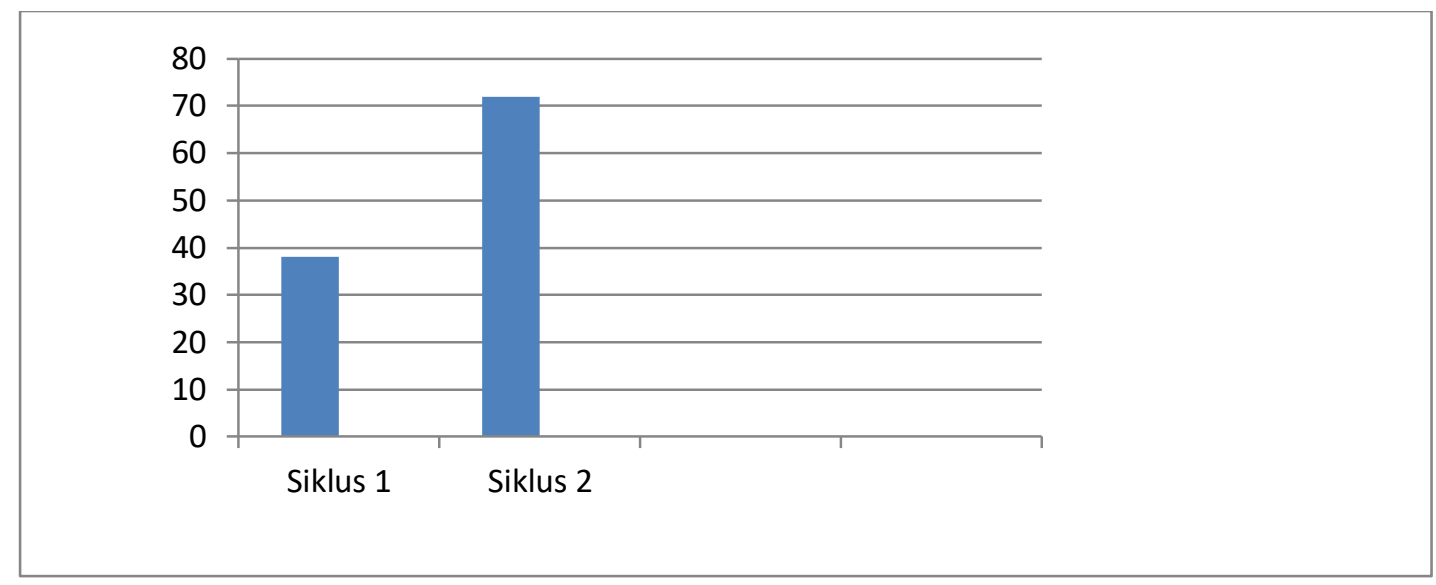

Gambar 1. Rata-rata aktivitas belajar siswa siklus 1 dan siklus 2

Jumlah siswa yang menyimak penjelasan guru, pada pertemuan pertama ke pertemuan ke dua mengalami peningkatan dari 7 orang siswa pada pertemuan pertama menjadi 10 orang pada pertemuan kedua, hal ini menunjukan keseriusan siswa dalam mengikuti proses pembelajaran. jumlah siswa yang mengajukan dan menjawab pertanyaan pada hasil observasi pertemuan pertama sampai pertemuan ketiga siklus I meningkat 4 orang siswa pada pertemuan pertama menjadi 8 orang pada pertemuan ke dua. Hal ini menunjukan tingginya perhatiannya siswa terhadap materi pelajaran, meskipun dalam hal ini hanya siswa yang pintar saja yang tergolong berani. Keaktifan siswa dalam menjawab pertanyaan guru, ini tampak pada hasil observasi dimana pada pertemuan pertama terdapat 6 orang siswa menjadi 8 orang pada pertemuan kedua. Hal ini menunjukkan adanya kesadaran siswa untuk belajar dan mengulang pelajaran dirumah. Keaktifan siswa mengajukan pendapat (Hading,2017), hal ini dapat dilihat dari siswa yang memberikan tanggapan sendiri mengalami peningkatan yaitu 3 siswa pada pertemuan pertama menjadi 7 orang siswa pada pertemuan kedua, hal ini dapat dilihat dari kemampuan siswa memberikan jawaban sendiri saat guru mengajukan pertanyaan. Siswa tidak percaya diri, pada pertemuan pertama ke pertemuan berikutnya mengalami penurunan dari pertemuan pertama terdapat 12 orang siswa dan menurun pada pertemuan kedua yaitu 7 orang siswa. Keaktifan siswa dalam kelas ditunjukan dengan kerjasama dalam kelompok (mengerjakan LKS) meningkat dan 5 orang siswa pada pertemuan pertama menjadi 12 orang siswa pada pertemuan kedua, hal ini menunjukan tingginya minat siswa belajar dengan menerapkan metode ceramah, diskusin, tugas. Jumlah siswa yang meminta bimbingan guru mengalami penurunan dan 15 orang siswa pada pertemuan pertama menurun menjadi 13 orang 
siswa pada pertemuan kedua. Jumlah siswa yang menyimpulkan jawaban teman meningkat dan pertemuan pertama sampai pertemuan ketiga. Ini nampak pada jumlah siswa pada pertemuan pertama sebanyak 7 orang siswa meningkat 10 orang siswa pada pertemuan kedua, hal ini menunjukan tingkat motivasi siswa dalam belajar. Demikian pula kesadaran siswa untuk tidak melakukan kegiatan lain dalam kelas selama proses pembelajaran berlangsung pada siklus pertama mengalami peningkatan hal ini dapat dilihat dan penurunan jumlah siswa yang melakukan kegiatan seperti bermain, menggangu teman, ribut,dan keluar masuk kelas (Arwin, 2019). Ini terlihat 8 orang siswa pada pertemuan pertama menurun menjadi 5 orang siswa pada pertemuan. Meskipun hal ini belum sepenuhnya dapat diatasi.

\section{b) Hasil Belajar}

Data hasil belajar siswa selama proses pembelajaran berlangsung diambil dengan menggunakan soal hasil belajar sebagai berikut :

Tabel 3. Distribusi frekuensi kategori hasil belajar siswa pada siklus 1

\begin{tabular}{llcc}
\hline Interval & Kategori & Frekuensi & Persentase \\
\hline $85-100$ & Sangat Tinggi & 3 & 15 \\
$75-84$ & Tinggi & 2 & 10 \\
$65-74$ & Sedang & 2 & 10 \\
$41-64$ & Rendah & 11 & 55 \\
$0-40$ & Sangat Rendah & 2 & 10 \\
& Total & $\mathbf{2 0}$ & $\mathbf{1 0 0 \%}$ \\
\hline
\end{tabular}

Tabel 4. Distribusi frekuensi kategori hasil belajar siswa pada siklus 2

\begin{tabular}{llcc}
\hline Interval & Kategori & Frekuensi & Persentase \\
\hline $85-100$ & Sangat Tinggi & 7 & 35 \\
$75-84$ & Tinggi & 9 & 45 \\
$65-74$ & Sedang & 2 & 10 \\
$41-64$ & Rendah & 2 & 10 \\
$0-40$ & Sangat Rendah & 0 & 0 \\
& Total & $\mathbf{2 0}$ & $\mathbf{1 0 0 \%}$ \\
\hline
\end{tabular}




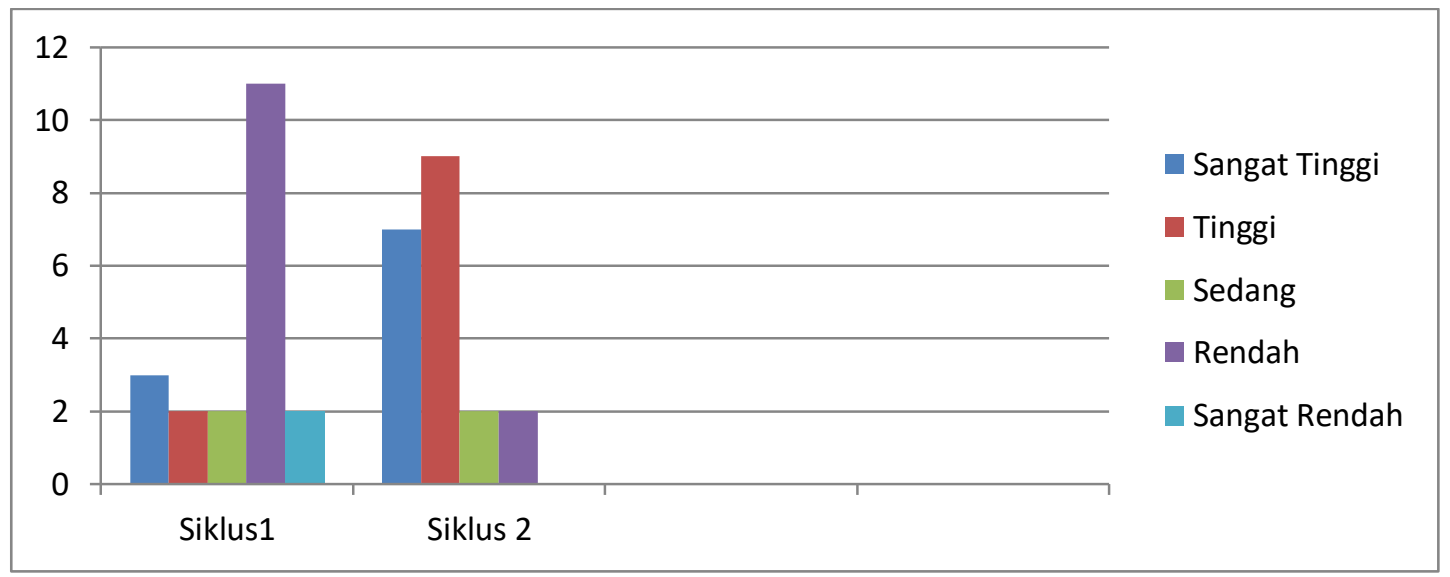

Gambar 2. Diagram hasil belajar siswa siklus 1 dan siklus 2

Penguasaan siswa setelah menggunakakan metode Pembelajaran Group to Group Exchange dengan media Mind Mapping pada sklus I terdapat 3 siswa atau 15\%, siklus II terdapat 7 siswa atau $35 \%$ berada pada kategori sanggat tinggi, pada siklus I terdapat 2 siswa atau 10\%, pada siklus II terdapat 9 siswa atau $45 \%$ yang berada dalam kategori tinggi, siklus I terdapat 2 siswa atau $10 \%$ pada siklus II terdapat 2 siswa atau $10 \%$ berada pada kategori sedang, 11 siswa atau 55\% pada siklus I sedangkan pada siklus II terdapa 2 siswa atau 10\% berada dalam kategori rendah dan 2 siswa atau 10\% siklus I sedangkan pada siklus II terdapat 0\% berada pada kategori sangat rendah. Dengan demikian dapat disimpulkan bahwa penguasaan siswa setelah menerapkan model pembelajaran Group to Group Exchange dengan media Mind Mapping pada siklus I dan siklus II terjadi peningkatan hasil belajar siswa yaitu dari siklus I ke siklus II dengan pencapaian kategori yang sangat memuaskan pada siklus II.

\section{c) Ketuntasan Hasil Belajar}

Tingkat ketuntasan hasil belajar siswa dapat dilihat dari nilai yang diperoleh siswa setelah mengikuti evaluasi belajar siklus I dan siklus II adapun ketuntasan dapat dilihat pada tabel 5 dibawah ini

Tabel 5. Ketuntasan hasil belajar siklus 1 dan siklus 2

\begin{tabular}{lcccc}
\hline \multirow{3}{*}{ Kriteria } & \multicolumn{3}{c}{ Siklus 1 } & \multicolumn{2}{c}{ Siklus 2 } \\
\cline { 2 - 5 } & F & \% & F & \% \\
Tuntas & 7 & 35 & 18 & 90
\end{tabular}




\begin{tabular}{lllll}
\hline Tidak Tuntas & 13 & 65 & 2 & 10 \\
Jumlah & $\mathbf{2 0}$ & $\mathbf{1 0 0}$ & $\mathbf{2 0}$ & $\mathbf{1 0 0}$ \\
\hline
\end{tabular}

Perbandingan hasil belajar siswa pada siklus I berada pada kategori tuntas hanya $35 \%$ dan meningkat pada siklus II dengan kategori tuntas 90\%, berarti peningkatan tingkat ketuntasan siswa ada pada siklus II. Adanya peningkatan memberikan indikasi bahwa penggunaan metode pembelajaran ceramah dengan menggunakan media audiovisual dapat berhasil meningkatkan hasil belajar siswa.karena jumlah siswa yang tuntas sebanyak 72,78\% mencapai nilai belajar secara klasikal yaitu $70 \%$. Bagi siswa yang tidak tuntas akan dilakukan remedial untuk memperoleh kelulusan. Penggunaan metode pembelajaran Group to Group Exchange dengan media Mind Mappingdi kelas VIII SMPN 6 Lembor Selatan yang dilaksanakan diharapakan siswa senantiasa berpikir lebih kreatif dan memiliki motivasi dalam mengikuti proses belajar mengajar. Hal ini sesuai yang pendapat Rahayu (2018) yang mengemukakan bahwa penggunaan metode pembelajaran Group to Group Exchange pesert didik mampu bernteraksi secara terbuka, berdialog dan intereaktif di bawah bimbingan guru sehingga peserta didik termotivasi untuk menguasai bahan ajar yang disajikan. Hasil yang baik menunjukan bahwa siswa sangat menyukai dan mengikuti proses dari awal hingga akhir pembelajaran dengan baik.

\section{KESIMPULAN DAN SARAN}

\section{Kesimpulan}

Berdasarkan data hasil penelitian menunjukan bahwa metode pembelajaran Group to Group Exchange dengan media Mind Mapping dapat meningkatkan hasil belajar siswa yang ditandai dengan peningkatan ketuntasan belajar siswa dalam setiap siklus. Pada siklus I skor rata-rata aktivitas siswa adalah 38,90 dan pada siklus II meningkat menjadi 72,78. Sedangkan jumlah siswa yang tidak tuntas pada siklus I adalah 65\% menurun pada siklus II 10\% dari 20 orang siswa. Penggunaan metode pembelajaran Group to Group Exchange dengan media Mind Mapping mampu memberikan pengaruh yang sangat baik untuk hasil belajar siswa di sekolah. Guru dianjurkan untuk menerapkan dan melaksanakan pembelajaran dengan baik serta adanya variasi dalam mengajar sehingga penggunaan metode ini salah satu jalan keluar ketika terjadi kesenjagan dalam hal hasil belajar siswa. 


\section{Saran}

Penulis berharap agar penellitian ini dapat dijadikan sebagai sumber informasi mengenai metode pembelajaran, selain itu penulis juga menyadari betul berbagai kekurangan dalam peelitian ini karena berbagai faktor, seperti keterbatasan sumber daya, biaya, waktu dan pendukung lainnya. Selain itu disarankan juga untuk penelitian selanjutnya agar melakukan penelitian dengan metode yang lain dan objek yang lain sehingga mampu memperkaya keilmuan dalam dunia pendidikan.

\section{DAFTAR RUJUKAN}

Hading, R. 2017. Pengaruh Strategi Group To Group Exchange Berbasis Eksperimen Terhadap Hasil Belajar Fisika.Jurnal Pendidikan Fisika. UIN Alaudin Makassar.

Rahayu, H. 2018. Pengaruh Model Pembelajaran Group To Group Exchangeberbantuan Lembar Kerja Peserta Didik Pada Mata Pelajaran Ekonomi. Jurnal Profit Volume. Universitas Sriwijaya.

Hamalik, O. 2005.Pendidikan Guru Berdasarkan Kompetensi. Yogyakarta: PT. Bumi Askara. Trianto, 2007.Model pembelajaran terpadu. Jakarta: Bumi Askara.

Silberman, M. 2013. Strategi Belajar Mengajar. Jakarta: Bumi Askara.

Buzan, T. 2004. Buku Pintar Mind Mapping.Jakarta: PT GramediaPustaka.

Majid, A. 2005.Mengembangkan perencanaan pembelajaran. Jakarta: Bumi Askara. 